\title{
Changes to magnetic minerals caused by frictional heating during the 1999 Taiwan Chi-Chi earthquake
}

\author{
Toshiaki Mishima ${ }^{1}$, Tetsuro Hirono ${ }^{2}$, Norihiro Nakamura ${ }^{3}$, Wataru Tanikawa ${ }^{4}$, Wonn Soh ${ }^{4}$, and Sheng-Rong Song ${ }^{5}$ \\ ${ }^{1}$ Research Center for Inland Seas, Kobe University, Kobe, Japan \\ ${ }^{2}$ Department of Earth and Space Science, Graduate School of Science, Osaka University, Toyonaka, Japan \\ ${ }^{3}$ Department of Geoenvironmental Science, Graduate School of Science, Tohoku University, Sendai, Japan \\ ${ }^{4}$ Kochi Institute for Core Sample Research, Japan Agency for Marine-Earth Science and Technology, Nankoku, Japan \\ ${ }^{5}$ Department of Geosciences, National Taiwan University, Taipei, Taiwan
}

(Received September 5, 2008; Revised November 28, 2008; Accepted December 25, 2008; Online published July 27, 2009)

\begin{abstract}
We carried out magnetic mineral analyses of samples from the shallowest major fault zone within the Chelungpu fault system, which is the zone that previous researchers believe slipped during the 1999 Taiwan Chi-Chi earthquake. Our aim was to gain an understanding of the changes to magnetic minerals during the earthquake. Magnetic hysteresis and low-temperature thermal demagnetization measurements showed that high magnetic susceptibilities in the black gouge zone within the major fault zone could be attributed not to fining of ferrimagnetic minerals but, rather, to their abundance. Thermomagnetic analyses indicated that the strata in and around the fault zone originally contained thermally unstable iron-bearing paramagnetic minerals, such as pyrite, siderite, and chlorite. We therefore concluded that frictional heating $\left(>400^{\circ} \mathrm{C}\right)$ occurred in the black gouge zone in the major fault zone during the slip of the Chi-Chi earthquake and that the resultant high temperature induced thermal decomposition of paramagnetic minerals to form magnetite, resulting in the observed high magnetic susceptibilities.
\end{abstract}

Key words: Frictional heating, 1999 Taiwan Chi-Chi earthquake, Chelungpu fault, ferrimagnetic mineral.

\section{Introduction}

The 1999 Taiwan Chi-Chi earthquake $\left(M_{\mathrm{w}} 7.6\right)$, with epicenter at lat 23.853, long 120.816, and a focal depth of $8 \mathrm{~km}$ (Ma et al., 1999), occurred on 21 September 1999 (Fig. 1). The earthquake initiated on the southern Chelungpu fault and ruptured both upward and laterally northward. The largest ground velocities and displacements, up to $3 \mathrm{~m} / \mathrm{s}$ and $8 \mathrm{~m}$, respectively, were recorded at the northern end of the Chelungpu fault, where the level of high-frequency radiation was lower than at the southern end (Shin and Teng, 2001). These seismological characteristics may reflect a low level of friction on the fault plane in the northern area (e.g., Ma et al., 2003).

The Taiwan Chelungpu-fault Drilling Project (TCDP) was started in 2002 to investigate the faulting mechanism of the Chi-Chi earthquake. Two boreholes were drilled, Holes A and B, penetrating the Chelungpu fault. Hole B was drilled to a depth of $1,352.60 \mathrm{~m}$, but core samples were recovered only from between 948.42 and $1,352.60 \mathrm{~m}$. Three dominant fault zones, FZB1136 (fault zone around 1,136 m in depth in Hole B), FZB1194, and FZB1243, were observed within the Chinshui Shale (Fig. 1); these were interpreted as segments of the Chelungpu fault (Hirono et al., 2006b, 2007). FZB1136 was thought to be most likely related to the 1999 Chi-Chi earthquake because it shows evidence of recent heating, low seismic velocity, and low elec-

Copyright (c) The Society of Geomagnetism and Earth, Planetary and Space Sciences (SGEPSS); The Seismological Society of Japan; The Volcanological Society of Japan; The Geodetic Society of Japan; The Japanese Society for Planetary Sciences; TERRAPUB trical resistivity, and also because a major stress orientation anomaly was observed in and around FZA1111 (which correlates to FZB1136 in Hole B) (Kano et al., 2006; Wu et al., 2007).

The detection of evidence of frictional heating in faultrelated rock samples is crucial to understanding the faulting mechanisms during earthquakes. High fluid pressures generated by shear-related heating cause thermal pressurization, that reduces the fault strength during seismic slip (e.g., Sibson, 1973; Lachenbruch, 1980). Frictional melting is promoted by frictional heating on the fault. Therefore, information about temperatures in earthquake faults is important.

Ikehara et al. (2007) measured carbon contents in core samples from each of the three major fault zones in TCDP Hole B and reported a remarkably low inorganic carbon content in the black gouge zones within each of them. These researchers suggested that these zones had been subjected to high temperatures, because thermal decomposition of carbonate minerals occurs at temperatures above approximately $400^{\circ} \mathrm{C}$ (Warne and French, 1984). In addition, Hirono et al. (2006b, 2007) reported high magnetic susceptibilities in the black gouge within each of the major fault zones, and proposed two possible explanations: (1) ferrimagnetic grains were crushed into submicrometer size by shearing, while the total concentration of magnetic mineral did not change or (2) magnetite or maghemite grains were newly formed by thermal decomposition of paramagnetic phases such as siderite (Pan et al., 2000).

Although we concluded from our previous magnetic 

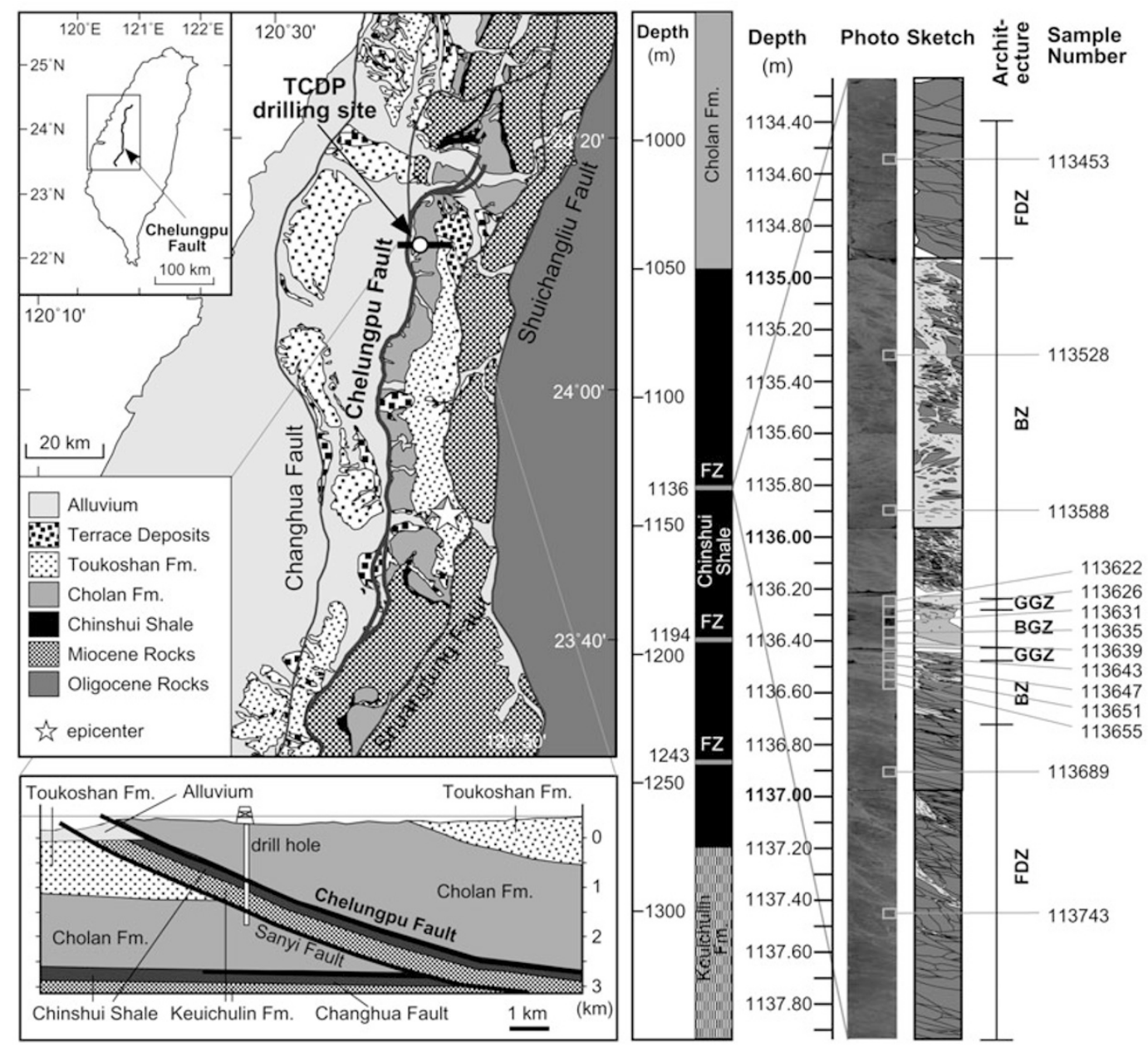

Fig. 1. Geological map of central Taiwan showing the site of the Taiwan Chelungpu-fault Drilling Project (TCDP) (after Hirono et al., 2006b), an E-W cross section through the drill hole site, and a core photo and interpretive sketch around the black gouge zone in FZB1136. The small boxes annotated on the core photo indicate the sampling points for magnetic mineral analyses. FZ, Fault zone; FDZ, fracture-damaged zone; BZ, breccia zone; GGZ, gray gouge zone; BGZ, black gouge zone. Samples 113626, 113631, and 113635 were corrected from BGZ, and 113622, 113639 , and 113643 were from GGZ.

analyses that the formation of magnetic minerals from paramagnetic minerals was the cause of the high magnetic susceptibility (Mishima et al., 2006), the samples analyzed were restricted to the disk-shaped black material and surrounding rocks within FZB1194 and FZB1243. The diskshaped black material has been identified as pseudotachylyte on the basis of its low degree of melting (Hirono et al., 2006a). Because FZB1136 was most likely related to the 1999 Chi-Chi earthquake (Kano et al., 2006; Wu et al., 2007), the high magnetic susceptibility in the black gouge zone within FZB1136 is considered to be representative of the temperatures of that event. Therefore, to determine magnetic mineralogy and granulometry and to investigate possible magnetic changes caused by a temperature increase, we applied three magnetic analysis methods to samples from FZB1136: magnetic hysteresis measurement, low-temperature thermal demagnetization, and thermomagnetic analyses.

\section{Sample Descriptions}

The following subzones were encountered in FZB1136, from top to bottom (Fig. 1): upper fracture-damaged zone $(1,134.40-1,134.93 \mathrm{~m})$, upper breccia zone
$(1,134.93-1,136.22 \mathrm{~m})$, upper gray gouge zone $(1,136.22-$ $1,136.26 \mathrm{~m})$, black gouge zone $(1,136.26-1,136.40 \mathrm{~m})$, lower gray gouge zone $(1,136.40-1,136.46 \mathrm{~m})$, lower breccia zone $(1,136.46-1,136.70 \mathrm{~m})$, and lower fracturedamaged zone $(1,136.70-1,137.90 \mathrm{~m})$.

High magnetic susceptibilities and low inorganic carbon contents have been reported previously in the black gouge zone (Hirono et al., 2006b, 2007; Ikehara et al., 2007), and an intense 20-mm-thick shear zone within the black gouge zone is considered to have been the most likely slip zone during the 1999 Chi-Chi earthquake (Ma et al., 2006; Hirono et al., 2008).

We collected 14 samples from FZB1136 (Fig. 1). Each sample spanned a depth of 4-5 cm, except for sampling from the black gouge zone, which was continuous. From the other zones, two or three representative samples were collected. Small subsamples weighing 10-50 mg were used for hysteresis measurements, and subsamples weighing 20$300 \mathrm{mg}$ were used for thermomagnetic analyses and lowtemperature measurements. 


\section{Methods}

Magnetic hysteresis was measured with a MicroMag alternating gradient field magnetometer. Paramagnetic susceptibility $\left(\chi_{\text {para }}\right)$ was calculated as the high-field (above $0.7 \mathrm{~T}$ ) slope of each hysteresis loop, with a maximum field of $1 \mathrm{~T}$. Saturation magnetization $\left(M_{\mathrm{S}}\right)$ and saturation remanence $\left(M_{\mathrm{r}}\right)$ were calculated from each slope-corrected hysteresis loop.

Low-temperature isothermal remanent magnetization (IRM) data were acquired at $10 \mathrm{~K}$ in a $1-\mathrm{T}$ magnetic field after cooling the sample from room temperature to $10 \mathrm{~K}$ in a zero magnetic field. Loss of IRM was monitored at intervals of 1 min during heating of the sample to $300 \mathrm{~K}$ at rates of $1 \mathrm{~K} / \mathrm{min}$ (between 10 and $150 \mathrm{~K}$ ) and $2 \mathrm{~K} / \mathrm{min}$ (between 150 and $300 \mathrm{~K})$.

Thermomagnetic analyses were carried out with a Natsuhara Giken NMB-89 thermobalance. The samples were heated to $600^{\circ} \mathrm{C}$ and then cooled to room temperature at a rate of $6^{\circ} \mathrm{C} / \mathrm{min}$ in a magnetic field of $0.4 \mathrm{~T}$ in air at atmospheric pressure. Changes in the induced magnetization were monitored at 1 -s intervals.

\section{Results}

\subsection{Magnetic hysteresis measurements}

The samples from the black gouge zone (113626, 113631, and 113635) showed broad hysteresis loops saturating below $0.3 \mathrm{~T}$ (Fig. 2), indicating the dominance of low-coercivity ferrimagnetic contributions with paramagnetic and superparamagnetic components. In contrast, samples from the gray gouge, breccia, and fracture-damaged zones were characterized by almost completely reversible loops. Some samples from these zones (e.g., 113622 and 113743) exhibited entirely paramagnetic behavior, that is, with a uniform slope of magnetization versus magnetizing field. Some samples showed closed S-shaped loops, suggesting a minor contribution of superparamagnetic and/or multidomain ferrimagnetic minerals in addition to paramagnetic phases.

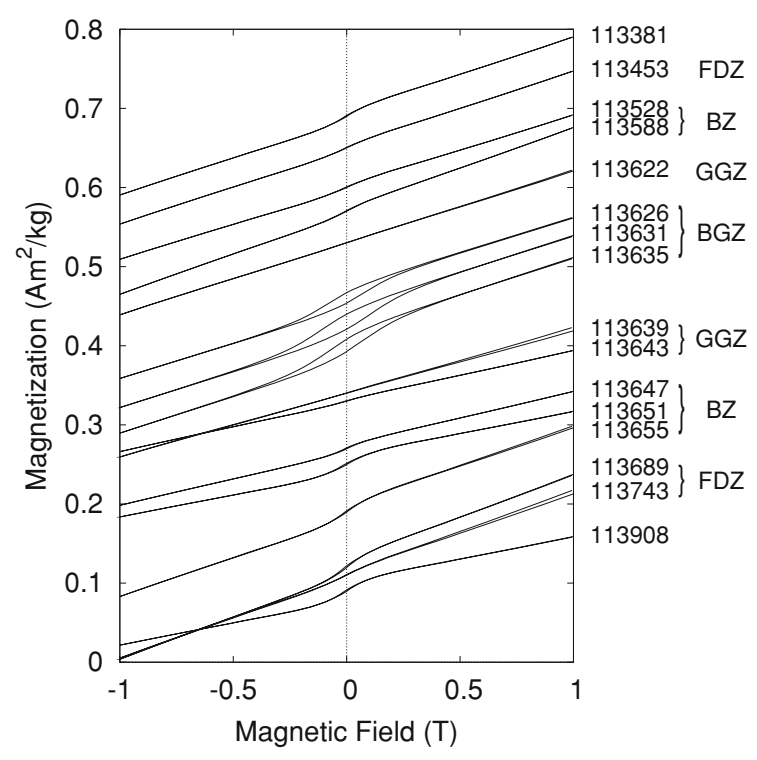

Fig. 2. Magnetic hysteresis loops for the samples from FZB1136.

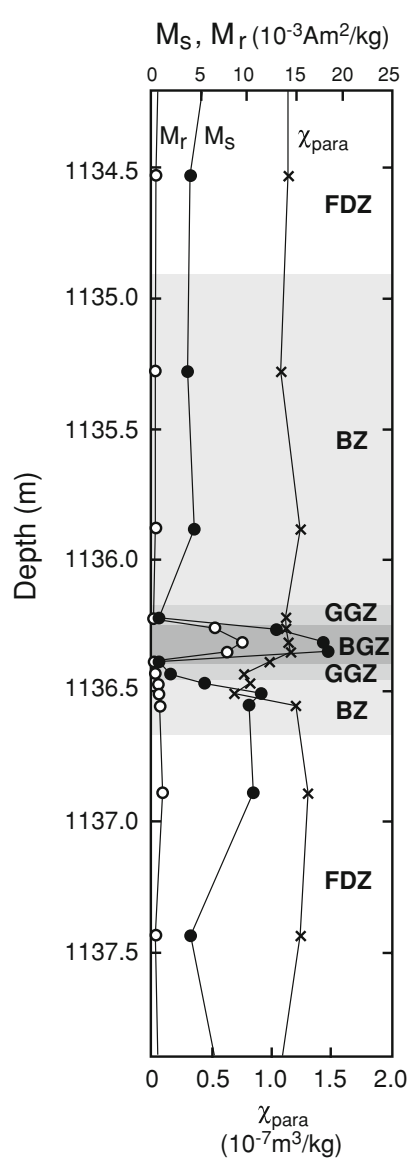

Fig. 3. Paramagnetic susceptibility ( $\left.\chi_{\text {para }}\right)$, saturation magnetization $\left(M_{\mathrm{S}}\right)$, and saturation remanence $\left(M_{\mathrm{r}}\right)$ plotted against depth. Each number in the plot indicates sample depth $(\mathrm{cm})$.

Paramagnetic susceptibility $\left(\chi_{\text {para }}\right)$, saturation magnetization $\left(M_{\mathrm{s}}\right)$, and saturation remanence $\left(M_{\mathrm{r}}\right)$ were plotted against the depth (Fig. 3). The values of $\chi_{\text {para }}$ para ranged between $0.69 \times 10^{-7}$ and $1.31 \times 10^{-7} \mathrm{~m}^{3} / \mathrm{kg}$ and did not change notably within the black gouge zone. In contrast, $M_{\mathrm{s}}$ and $M_{\mathrm{r}}$ were remarkably high within the black gouge zone $\left(13.0 \times 10^{-3}\right.$ to $18.5 \times 10^{-3} \mathrm{Am}^{2} / \mathrm{kg}$ and $6.6 \times 10^{-3}$ to $9.5 \times 10^{-3} \mathrm{Am}^{2} / \mathrm{kg}$, respectively). The ratio $M_{\mathrm{s}} / M_{\mathrm{r}}$ ranged between 0.269 and 0.521 within the black gouge zone, suggesting dominance of single-domain to pseudosingle-domain ferrimagnetic grains.

\subsection{Low-temperature measurements}

Thermal demagnetization curves for low-temperature IRM in the samples from FZB1136 (Fig. 4) show that the remanence loss below $30 \mathrm{~K}$ in the black gouge samples (19.1-24.0\%) was smaller than the loss in the samples from the gray gouge, breccia, or fracture-damaged zones (86.6$94.0 \%$ ). A very slight loss of magnetization at about $120 \mathrm{~K}$ was discerned in the samples from gray gouge, breccia, and fracture-damaged zones.

\subsection{Thermomagnetic analyses}

The thermomagnetic curves of samples from the gray gouge zone and breccia zone (Fig. 5) are characterized by humps above $400^{\circ} \mathrm{C}$. Induced magnetization during heating began to increase at about $400^{\circ} \mathrm{C}$, reached a maximum at about $460-480^{\circ} \mathrm{C}$, and then decreased from 480 to $600^{\circ} \mathrm{C}$. During cooling from $600^{\circ} \mathrm{C}$, the induced mag- 


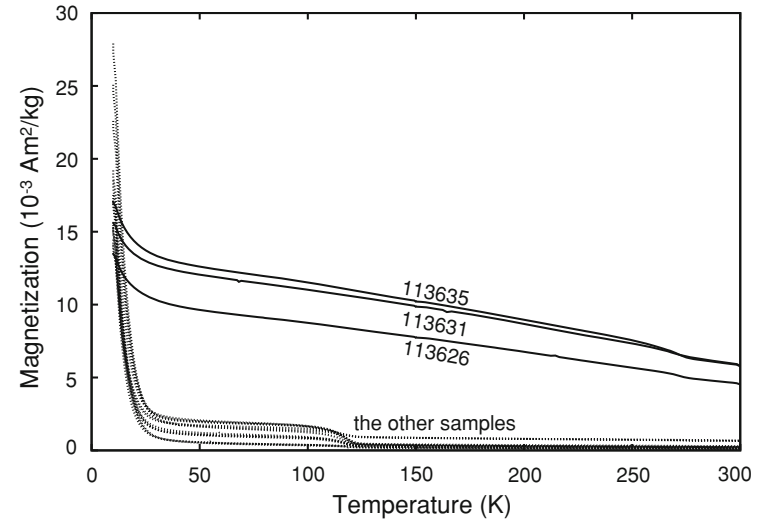

Fig. 4. Thermal demagnetization curves of low-temperature IRM for samples from FZB1136.

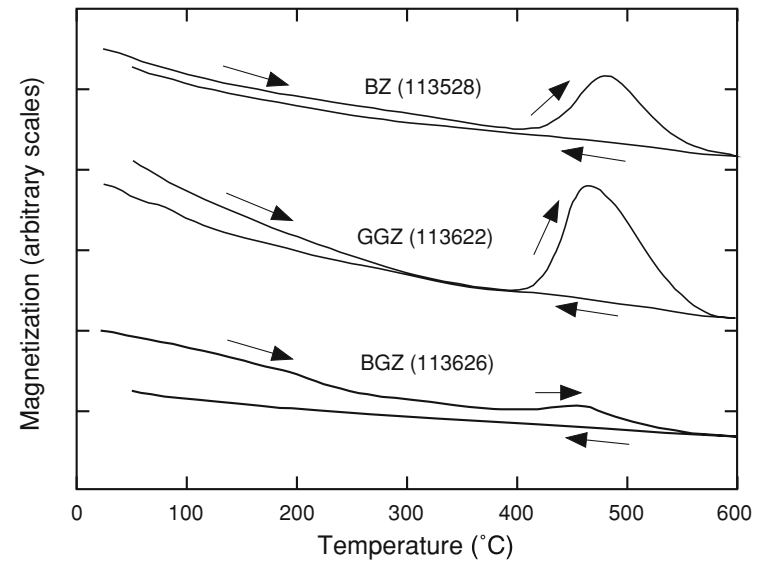

Fig. 5. Thermomagnetic curves for samples from the black gouge zone (113626), gray gouge zone (113622), and breccia zone (113528) of FZB1136.

netization increased monotonously but remained below the levels recorded during heating. The thermomagnetic curve of the sample from the black gouge zone also shows humps at $400-600^{\circ} \mathrm{C}$, but the increase of induced magnetization at the hump is much lower than those of samples from the gray gouge and breccia zones.

\section{Discussion}

We first examined the cause of the high magnetic susceptibility in the black gouge zone. Magnetic hysteresis loops in samples from the black gouge zone showed a nonlinear slope for magnetization plotted against magnetizing field, whereas the hysteresis loops for samples from the surrounding zones showed relatively high contributions of paramagnetic phases (Fig. 3). This suggests that the contribution of ferrimagnetic minerals to magnetic susceptibility was dominant only in the black gouge zone. The $\chi_{\text {para }}$ values $\left(0.69 \times 10^{-7}\right.$ to $\left.1.31 \times 10^{-7} \mathrm{~m}^{3} / \mathrm{kg}\right)$ are equivalent to $15 \times 10^{-5}$ to $29 \times 10^{-5} \mathrm{SI}$ and may correspond to a larger portion of magnetic susceptibility $\left(30 \times 10^{-5}\right.$ to $60 \times 10^{-5}$ SI; Hirono et al., 2006a). The high values of $M_{\mathrm{s}}$ and $M_{\mathrm{r}}$ in the black gouge zone clearly indicate an abundance of ferrimagnetic minerals, and might be related to the high magnetic susceptibilities there. The concentration of ferrimagnetic minerals was estimated to be 0.014 to $0.020 \mathrm{wt} \%$
(0.014 wt $\%$ for $113626,0.019 \mathrm{wt} \%$ for $113631,0.020 \mathrm{wt} \%$ for 113635), supposing that dominating ferrimagnetic minerals was magnetite $\left(M_{\mathrm{s}}\right.$ and density are $4.80 \times 10^{5} \mathrm{~A} / \mathrm{m}$ and $\left.5.197 \times 10^{3} \mathrm{~kg} / \mathrm{m}^{3}\right)$.

Crushing of the ferrimagnetic grains to submicrometer superparamagnetic size by shearing during the earthquake is another possible cause of the high magnetic susceptibilities (Hirono et al., 2006b). Suppression of low-temperature IRM decay at $120 \mathrm{~K}$ in samples from black gouge zone (Fig. 4) suggests a certain degree of magnetic grain size reduction (Özdemir et al., 1993). However, the broad hysteresis loops and high $M_{\mathrm{r}} / M_{\mathrm{s}}$ ratios of the samples from the black gouge zone (Figs. 3 and 4) suggest that the range of grain size of the ferrimagnetic minerals represents stable single-domain to pseudo-single-domain sizes and is not small enough for significant magnetic susceptibility increase.

The amount of decrease in remanent magnetization on a low-temperature demagnetization curve is useful for estimating the quantity of superparamagnetic grains (Hunt and Banerjee, 1992; Hunt et al., 1995); it was smaller in the black gouge zone than in other zones (Fig. 4), indicating that there were fewer superparamagnetic grains in the black gouge zone than in the other zones. Therefore, fining of ferrimagnetic minerals is not a plausible explanation for the observed high magnetic susceptibility in the black gouge zone.

We next considered the origin of the ferrimagnetic minerals in the black gouge zone. Humps are observed on the thermomagnetic curves for many thermally unstable iron-bearing minerals and can be interpreted to reflect the thermal decomposition of siderite (Pan et al., 2000), lepidocrosite (Özdemir and Dunlop, 1993), or ferrimagnetic iron sulfide (Snowball and Torii, 1999) to form magnetite or maghemite. The samples from the gray gouge and breccia zones, both of which surround the black gouge zone, showed larger humps above $400^{\circ} \mathrm{C}$ than the sample from black gouge zone (Fig. 5). The humps suggest the existence of thermally unstable iron-bearing minerals that can be transformed to magnetite or maghemite at temperatures above $400^{\circ} \mathrm{C}$. The smaller hump of the black gouge zone sample suggests that a larger portion of such minerals were already transformed to magnetite or maghemite due to high temperature, as demonstrated by repeated thermomagnetic analyses of the host rock samples around the fault zone (Mishima et al., 2006).

As no decrease in magnetization at the Curie temperature of pyrrhotite $\left(320^{\circ} \mathrm{C}\right)$ or greigite $\left(250^{\circ} \mathrm{C}\right)$ was recognized in the thermomagnetic curves of the samples from the gray gouge and breccia zones, the thermally unstable iron-bearing minerals in these samples may be paramagnetic. This may indicate that the paramagnetic minerals originally existed in and around the fault zone. Tanikawa et al. (2008) analyzed the thermomagnetic susceptibility of a sample from the host rock, located $2.5 \mathrm{~m}$ above the black gouge zone of FZB1136, and concluded that the original iron-bearing minerals were pyrite, siderite, and chlorite. Thus, their thermal decomposition to form magnetite or maghemite might have contributed to the high magnetic susceptibility when heated up to $710^{\circ} \mathrm{C}$. 


\section{Conclusion}

Magnetic hysteresis and low-temperature thermal demagnetization data from the fault-related samples from FZB1136 showed that high values of magnetic susceptibility in the black gouge zone could be attributed to an abundance of ferrimagnetic minerals rather than to the fining of ferrimagnetic minerals. Thermomagnetic analyses in this study and by Tanikawa et al. (2008) indicate that the strata in and around the fault zone originally contained thermally unstable iron-bearing paramagnetic minerals such as pyrite, siderite, and chlorite. Thus, we concluded that the high temperatures due to frictional heating $\left(>400^{\circ} \mathrm{C}\right)$ in the black gouge zone within FZB1136 during the slip of the 1999 Chi-Chi earthquake caused thermal decomposition of paramagnetic minerals to form magnetite, thus producing the observed high magnetic susceptibilities.

Acknowledgments. We thank Kazuto Kodama, Naoto Ishikawa, Weiren Lin, Osamu Tadai, Masumi Sakaguchi, Kuo-Fong Ma, JihHao Hung, and Chien-Ying Wang for their assistance with our analyses of Hole B core samples.

\section{References}

Hirono, T., M. Ikehara, K. Otsuki, T. Mishima, M. Sakaguchi, W. Soh, M. Omori, W. Lin, E. Yeh, W. Tanikawa, and C. Wang, Evidence of frictional melting within disk-shaped black materials discovered from the Taiwan Chelungpu fault system, Geophys. Res. Lett., 33, L19311, doi:10.1029/2006GL027329, 2006a.

Hirono, T., W. Lin, E. Yeh, W. Soh, Y. Hashimoto, H. Sone, O. Matsubayashi, K. Aoike, H. Ito, M. Kinoshita, M. Murayama, S. Song, K. Ma, J. Hung, C. Wang, and Y. Tsai, High magnetic susceptibility of fault gouge within Taiwan Chelungpu fault: Nondestructive continuous measurements of physical and chemical properties in fault rocks recovered from Hole B, TCDP, Geophys. Res. Lett., 33, L15303, doi:10.1029/2006GL026133, 2006b.

Hirono, T., E. Yeh, W. Lin, H. Sone, T. Mishima, W. Soh, Y. Hashimoto, O. Matsubayashi, K. Aoike, H. Ito, M. Kinoshita, M. Murayama, S. Song, K. Ma, J. Hung, C. Wang, Y. Tsai, T. Kondo, M. Nishimura, S. Moriya, T. Tanaka, T. Fujiki, L. Maeda, H. Muraki, T. Kuramoto, K. Sugiyama, and T. Sugawara, Nondestructive continuous physical property measurements of core samples recovered from Hole B, Taiwan Chelungpu-fault Drilling Project, J. Geophys. Res., 112, B07404, doi:10.1029/2006JB004738, 2007.

Hirono, T., M. Sakaguchi, K. Otsuki, H. Sone, K. Fujimoto, T. Mishima, W. Lin, W. Tanikawa, M. Tanimizu, W. Soh, E. Yeh, and S. Song, Characterization of slip zone associated with the 1999 Taiwan Chi-Chi earthquake: X-ray CT image analyses and microstructural observations of the Taiwan Chelungpu fault, Tectonophysics, 449, 63-84, 2008.

Hunt, C. P. and S. K. Banerjee, Thermal demagnetization of lowtemperature SIRM: a new method for magnetic granulometry (abstract), EOS Trans. AGU, 73, 138, 1992.

Hunt, C. P., S. K. Banerjee, J. M. Han, P. A. Solheid, E. Oches, W. Sun, and T. S. Liu, Rock-magnetic proxies of climate change in the loesspalaeosol sequences of the western Loess Plateau of China, Geophys. J. Int., 123, 232-244, 1995.

Ikehara, M., T. Hirono, O. Tadai, M. Sakaguchi, H. Kikuta, T. Fukuchi,
T. Mishima, N. Nakamura, K. Aoike, K. Fujimoto, Y. Hashimoto, T. Ishikawa, H. Ito, M. Kinoshita, W. Lin, K. Masuda, T. Matsubara, O. Matsubayashi, K. Mizoguchi, M. Murayama, K. Otsuki, H. Sone, M. Takahashi, W. Tanikawa, M. Tanimizu, W. Soh, and S. Song, Low total and inorganic carbon contents within the Chelungpu fault, Geochem. J., 41, 391-396, 2007.

Kano, Y., J. Mori, R. Fujio, H. Ito, T. Yanagidani, S. Nakao, and K. Ma, Heat signature on the Chelungpu fault associated with the 1999 Chi-Chi, Taiwan earthquake, Geophys. Res. Lett., 33, L14306, doi:10.1029/2006GL026733, 2006.

Lachenbruch, A. H., Frictional heating, fluid pressure, and the resistance to fault motion, J. Geophys. Res., 85, 6097-6122, 1980.

Ma, K. F., C. T. Lee, Y. B. Tsai, T. C. Shin, and J. Mori, The Chi-Chi Taiwan earthquake: large surface displacements on inland thrust fault, EOS, 80, 605-611, 1999.

Ma, K. F., E. E. Brodsky, J. Mori, T. A. Song, and H. Kanamori, Evidence for fault lubrication during the 1999 Chi-Chi, Taiwan, earthquake (Mw7.6), Geophys. Res. Lett., 30, 1244, doi:10.1029/2002GL015380, 2003.

Ma, K. F., H. Tanaka, S. Song, C. Wang, J. Hung, Y. Song, E. Yeh, W. Soh, H. Sone, L. Kuo, and H. Wu, Slip zone and energetics of a large earthquake from the Taiwan Chelungpu-fault Drilling Project, Nature, 444, 473-476, 2006.

Mishima, T., T. Hirono, W. Soh, M. Ikehara, W. Lin, W. Tanikawa, E. Yeh, S. Song, and C. Wang, Thermal history estimation of the Taiwan Chelungpu Fault using rock-magnetic methods, Geophys. Res. Lett., 33, L23311, doi:10.1029/2006GL028088, 2006.

Özdemir, Ö. and D. J. Dunlop, Chemical remanent magnetization during $\gamma \mathrm{FeOOH}$ phase transformations, J. Geophys. Res., 98, 4191-4198, 1993.

Özdemir, Ö., D. J. Dunlop, and B. M. Moskowitz, The effect of oxidation on the Verwey transition in magnetite, Geophys. Res. Lett., 20, 16711674, 1993.

Pan, Y. X., R. X. Zhu, S. K. Banerjee, J. Gill, and Q. Williams, Rock magnetic properties related to thermal treatment of siderite: Behavior and interpretation, J. Geophys. Res., 105, 783-794, 2000.

Shin, T. and T. Teng, An overview of the 1999 Chi-Chi, Taiwan, Earthquake, Bull. Seismol. Soc. Am., 91, 895-913, 2001.

Sibson, R. H., Interaction between temperature and pore-fluid pressure during earthquake faulting-A mechanism for partial or total stress relief, Nature, 243, 66-68, 1973.

Snowball, I. and M. Torii, Incidence and significance of magnetic iron sulphides in Quaternary sediments and soils, in Quaternary Climates, Environments and Magnetism, edited by B. A. Maher and R. Thompson, pp. 199-230, Cambridge University Press, Cambridge, 1999.

Tanikawa, W., T. Mishima, T. Hirono, W. Soh, and S. Song, High magnetic susceptibility produced by thermal decomposition of core samples from the Chelungpu fault in Taiwan, Earth Planet. Sci. Lett., 272, 372-381, 2008.

Warne, S. St. J. and D. H. French, The decomposition of anhydrous carbonate minerals in coal and oil shale ashes produced at temperatures of 400 and $575^{\circ} \mathrm{C}$, Thermochimica Acta, 75, 139-149, 1984.

Wu, H., K. Ma, M. Zoback, N. Boness, H. Ito, J. Hung, and S. Hickman, Stress orientations of Taiwan Chelungpu-Fault Drilling Project (TCDP) hole-A as observed from geophysical logs, Geophys. Res. Lett., 34, L01303, doi:10.1029/2006GL028050, 2007.

T. Mishima, T. Hirono (e-mail: hirono@ess.sci.osaka-u.ac.jp), N. Nakamura, W. Tanikawa, W. Soh, and S.-R. Song 